\title{
Antoine Lilti. La Ilustración, entre pasado y presente
}

\author{
Gabriela Goldin Marcovich
}

École des Hautes Études en Sciences Sociales / Duke University

Cuando le preguntan ¿por qué investiga?, Antoine Lilti responde "soy de aquellos historiadores a los que no les interesa demasiado el pasado... a mí el pasado me interesa en cuanto sigue presente". ${ }^{1}$ Director de estudios en la Escuela de altos estudios en ciencias sociales de París (EHESS), con una cátedra intitulada "Historia e historicidad de la Ilustración", Antoine Lilti fue anteriormente maître de conférences en la Escuela Normal Superior (2005-2011) y director de la revista Annales. Histoire, Sciences Sociales (2006-2011).

Formado en la tradición de la historia social y cultural francesa de Roger Chartier y Daniel Roche, con el que estudió su doctorado, Antoine Lilti es hoy en día una de las voces más importantes en la historiografía del siglo XVIII y de la Ilustración. No es difícil ver que sus temas de estudio corresponden a un pasado que sigue presente sin, obviamente, estarlo del todo. Lilti hace de esta ambigüedad temporal el centro de su labor historiográfica que él mismo define como una "relación irónica del historiador con sus objetos que nunca son exactamente lo que parecen ser". ${ }^{2}$

A contracorriente de la postura del historiador que pretende objetivar lo que estudia estableciendo la mayor distancia posible entre su persona y su trabajo, Lilti considera que es necesario tomar en serio las cadenas de interpretación que nos han transmitido los objetos culturales a lo largo de los siglos. ${ }^{3}$ Esta postura hermenéutica no supone renunciar a la metodología histórica. Por el contrario, cuando se hace historia se trata de efectuar una serie de operaciones de contextualización social y cultural. En suma, se trata de una "hermenéutica crítica".

Por ejemplo, en Le monde des salons (2005), Lilti demuestra cómo la noción misma de "salón", asociada tan fuertemente al siglo de las Luces, fue forjada en realidad en el siglo XIX y designa unas veces los salones literarios e ilustrados, otras veces los salones aristocráticos, ya sea lamentando nostálgicamente un modelo que se pierde o reprobando críticamente la

\footnotetext{
1 “Antoine Lilti et l'héritage des Lumières", entrevista en la serie "Pourquoi cherchez-vous?", de Geneviève Anhoury. Disponible en <https://www.youtube.com/watch?v=EijW5M34-qA>.

${ }^{2}$ Ibid.

${ }^{3}$ Antoine Lilti, "Rabelais est-il notre contemporain? Histoire intellectuelle et herméneutique critique", Revue d'histoire moderne et contemporaine, 2012, $\mathrm{n}^{\circ} 5$, pp. 65-84, p. 76.

${ }^{4}$ Ibid., pp. 82-83.
} 
mundanidad vana que permanece. ${ }^{5}$ En lugar de una historia de los "salones", propone una historia de las prácticas de sociabilidad mundanas de las élites parisinas en el siglo XVIII. Esto permite comprender la pluralidad de estos espacios sociales y la manera en que fungen como interfaz entre el mundo literario, político, filosófico y social, siguiendo las pistas abiertas por Norbert Elias. ${ }^{6}$

Asumir esta postura en cuanto historiador supone asumir también su propia relación subjetiva y presente con el pasado. ${ }^{7}$ El caso de la Ilustración es singular ya que, al designar no solo un período histórico sino también un proceso filosófico, su significado e importancia no dejan de ser reevaluados por una pluralidad de actores en el espacio público, con el fin de reactualizar sus supuestos valores en nuestras sociedades. Ante esta situación, lo que propone Lilti no podría estar más alejado de una defensa o de una denuncia de la Ilustración. Crítico de una historia desencarnada de las ideas, Lilti aboga por una articulación de la historia social y cultural con la historia intelectual, y más ampliamente con las ciencias sociales, siguiendo la tradición de la Escuela de los Annales. ${ }^{8}$

Este diálogo constante con las otras disciplinas y sus métodos se ve claramente en su trabajo sobre los inicios de la cultura de las celebridades en el siglo XVIII, Figures publiques: les origines de la célébrité (1750-1850), publicado en $2014 .{ }^{9} \mathrm{Al}$ analizar, por ejemplo, a Rousseau como una estrella pop, Lilti hace la apuesta de un uso asumido del anacronismo, considerado a menudo como el mayor enemigo del historiador. ${ }^{10}$ Gracias a este enfoque, pone de manifiesto la nueva relación entre el escritor, figura pública, y un público lector, deseoso de saber más sobre su vida privada. Cuando indaga la noción de celebridad e interroga sus mecanismos, logra situar las raíces de un fenómeno importante de nuestras sociedades -que podría parecer radicalmente nuevo- en las transformaciones técnicas y sociales del siglo XVIII que dieron lugar a una "primera revolución mediática", y a la emergencia de la publicidad y el público (paralelamente a la emergencia de lo privado y de lo íntimo) en sus acepciones modernas.

El siglo XVIII se caracteriza también por la mundialización a través del comercio y la "toma de conciencia europea" de su propia historicidad pensada como resultado de un proceso de "civilización", noción cargada de ambigüedades, en la confrontación con el resto de mundo y con el pasado. ${ }^{11}$ Son las ambigüedades mismas de los conceptos, y de la Ilustración en general, que Lilti interroga en su último libro L'héritage des Lumières. Ambivalences de la modernité (2019), cuya introducción traducida al español Prismas publica en este número. Esta obra

\footnotetext{
${ }^{5}$ Antoine Lilti, Le Monde des salons. Sociabilité et mondanité à Paris au XVIII siècle, París, Fayard, 2005.

${ }^{6}$ Sobre el concepto de sociabilidad véanse los trabajos fundamentales de Maurice Agulhon.

${ }^{7}$ Michel de Certeau, L'écriture de l'histoire, París, Gallimard, 1974, p. 119. Véase, por ejemplo, Antoine Lilti, "Une subtile trahison: l'historien et les siens", Critique, n 811, 2014, pp. 1019-1030.

${ }^{8}$ Véase, por ejemplo, la crítica de Lilti a la obra de Jonathan Israel, "Comment écrit-on l'histoire intellectuelle des Lumières? Spinozisme, radicalisme et philosophie?”, Annales HSS, 64-1, 2009, pp. 171-206, y su ensayo sobre la obra de Clare Haru Crowston, "Le pouvoir du crédit au XVIII ${ }^{\mathrm{e}}$ siècle: Histoire intellectuelle et sciences sociales", Annales HSS, 2015, $\mathrm{n}^{\circ}$ 4, pp. 957-977.

${ }^{9}$ Antoine Lilti, Figures publiques: les origines de la célébrité (1750-1850), París, Fayard, 2014.

${ }^{10}$ Antoine Lilti, "Rabelais est-il notre contemporain? Histoire intellectuelle et herméneutique critique", Revue d'histoire moderne et contemporaine, 2012, $\mathrm{n}^{\circ} 5$, pp. 67-68.

${ }^{11}$ Antoine Lilti, “La civilisation est-elle européenne? Écrire l'histoire de l'Europe au XVIII siècle”, en Antoine Lilti y Céline Spector, Penser l'Europe au XVIII' siècle. Commerce, Empire, Civilisation, Oxford University Studies in the Enlightenment, 2014, pp. 139-166, p. 140. Véase también del autor, "L'impossible histoire globale. Parcours de la 'civilisation"”, en Antoine Lilti, Sabina Loriga, Jean-Frédéric Schaub y Silvia Sebastiani, L'expérience historiographique. Autour de Jacques Revel, París, Éditions de l'EHESs, 2016, pp. 181-200.
} 
funciona como una síntesis de las reflexiones de Lilti sobre el siglo XVIII como un momento filosófico, histórico y político complejo en que la idea de Europa forma parte de controversias intelectuales a partir de diversos problemas: las civilizaciones, la legitimidad de la expansión colonial, la guerra, la paz y el comercio, la religión y la secularización, el ciudadano, la difusión de saberes, etc., en un constante diálogo con la historiografía y con el presente. 